\title{
The Language of ByZantine-Slavic Written Culture in Slovakia From an AXIOlOgical PoINT OF VIEW
}

\section{PETER ŽEŇUCH}

Jan Stanislav Institute of Slavistics, Slovak Academy of Sciences

peter.zenuch@savba.sk

Cyrillic written texts existing in the Slovak setting make up a unique circle of documents. Many Cyrillic texts have been copied or created as compilations from multiple sources. The language of these texts reflects the thinking of the people using it, which in its own right reflects the cultural thinking and education of Slovak believers of the Byzantine rite. The basis for the creation of these texts is the language of religion, in this case Church Slavonic, along with the entire liturgical terminological system.

Keywords: liturgical language, vernacular language, terminology, cultural awareness

\section{ЛИТЕРАТУРА / REFERENCES}

Кравецкий 1999: Кравецкий, А. Г. Литургический язык как предмет этнографии. - В: Агапкина Т. А., Л. Н. Виноградова, Е. Е. Левкиевская, А. А. Плотникова (eds.). Славянские этюды. Сборник к юбилею С. М. Толстого. Москва, Индрик, s. 232 [Kravetskii 1999: Kravetskii, A. G. Liturgicheskii iazyk kak predmet etnografii [Liturgical Language as a Subject of Ethnography].-In: Agapkina, T. A., L. N. Vinogradova, E. E. Levkievskaia, A. A. Plotnikova (eds.). Slavianskie etiudy. Sbornik k iubileiu S. M. Tolstogo. Moskva, Indrik, 1999, s. 232].

Dorula 1977: Dorul'a, Ján. Slováci v dejinách jazykových vzt’ahov. Bratislava: Vydavatel'stvo Slovenskej akadémie vied.

Dorula 2014: Dorul'a, Ján. Predstavy slovenských vzdelancov o jazyku a etnickej identite Slovákov v období národného obrodenia. - In: Dorul'a Ján (ed.). Historický význam a odkaz diela osobností slovenského národného obrodenia. Bratislava: Slavistický ústav Jána Stanislava SAV, 2014, s. 108.

Krajčovič 1974: Krajčovič, $R$. Slovenčina a slovanské jazyky. Praslovanská genéza slovenčiny. Bratislava: Slovenské pedagogické nakladatel'stvo. Stanislav, Ján: Starosloviensky jazyk 1. a 2. Bratislava: Slovenské pedagogické nakladatel'stvo, 1978 a 1987.

Pavlovič 1997: Pavlovič, Jozef. O niektorých problémoch prekladania textu Nového zákona. Dorul'a Ján (ed.). Bratislava: Slavistický kabinet SAV, s. 152-161.

Stsnislav 1978: Stsnislav, Ján. Starosloviensky jazyk 1. a 2. Bratislava: Slovenské pedagogické nakladatel'stvo, 1978 a 1987.

Zubko 2014: Zubko, P. Kult svätých Cyrila a Metoda v tradícii latinskej cirkvi. Vybrané kapitoly cyrilo-metodského kultu. Ružomberok: Verbum. $252 \mathrm{~s}$. 
Žeňuch 2011: Žeňuch, $P$. Z výskumu pomedzného užského nárečového areálu (na príklade nárečia obce Kaluža). - In: Slavica Slovaca, roč. 46, č. 1, s. 51-62.

Žeňuch 2012: Žeňuch, P. Nižnorybnický spevník z roku 1817 - znovuobjavený rukopis. - In: Slavica Slovaca, roč. 47, č. 2, s. 118-144.

Žeňuch 2013: Žeňuch, P. Byzantsko-slovanská kultúra na Slovensku - tradícia či import? - In: Kuczyńska, Marzanna, Stradomski, Jan (eds.). Krakowsko-Wileńskie studia slawistyczne 8 . Cyrylometodejski komponent kultury chrześcijańskiej Słowian w regionie karpackim. Historia, tradycje, odwołania. Kraków: Instytut Filologii Słowiańskiej UJ, Wydawnictwo „Scriptum“, s. 157-195.

Žeňuch 2014: Žeňuch, $P$. Kultúrne a spoločenské podmienky vydania pät’zväzkovej Biblie pre gréckokatolíkov Mukačevskej eparchie. - In: Dorula, Ján (ed.). Historický význam a odkaz diela osobností slovenského národného obrodenia. Bratislava: Slavistický ústav Jána Stanislava SAV, s. 131-160.

Žeňuch 2015: Žeňuch, $P$. K dejinám cyrilskej písomnej kultúry na Slovensku. Nitra: Univerzita Konštantína Filozofa, s. 25-26.

Žeňuchová 2013: Žeňuchová, K. Kánonické a nekánonické obrazy a l’udová religiozita v prozaickom folklóre slovensko-ukrajinských pohraničných oblastí. In: Žeňuch, Peter (ed.). XV. Medzinárodný zjazd slavistov v Minsku. Príspevky slovenských slavistov. Bratislava: Slovenský komitét slavistov - Slavistický ústav Jána Stanislava SAV, s. 155-170.

$\bowtie$ Prof. DSc Peter Žeňuch Slavistický ústav Jána Stanislava SAV Dúbravska cesta 9 84104 Bratislava, Slovensko 